\title{
Theology after Pandora
}

In these next three chapters, I explore the more or less anaphrodisiacal effects that different sorts of theology can have on people's desire to engage in religious sects. When it comes to bearing gods, fundamentalist religious groups are far more fertile than liberal religious groups. Demographically, the same is true for bearing babies. This is one of the reasons why mainstream, progressive denominations have declined while many charismatic and conservative denominations have grown, or at least come closer to maintaining their population levels. However, I will argue that liberal permissivism is at least as problematic as conservative fertility (though for different reasons).

In this chapter, I clarify the tension between the sacerdotal and iconoclastic trajectories of theology in the work of one of most progressive theologians in the evangelical tradition. Chapter 8 assesses the "natural theology" of a theologian who has devoted much of her scholarly efforts to reconstructing Christian doctrine in light of challenges from evolutionary biology and climate science. Chapter 9 examines the (relatively) theolytic writings of one of the world's leading liberal theologians committed to a radically pluralistic approach to religion.

Each of these theologians is (more or less) critical of some of the godconceptions in the Christian tradition and some of the repressive and oppressive effects of the religious coalitions with which they are affiliated. For this, the atheist can be grateful. For reasons I hope to make increasingly clear, however, this kind of "critical" theological reflection all too easily provides cover for the religious reproduction of the sort of superstitious beliefs and segregative behaviors that are exacerbating the global (and local) challenges we all face.

The evangelical theologian Stanley Grenz loved to make connections between theology and popular culture, and he had a special predilection for science fiction - especially Star Trek (Next Generation, of course) and X-Files (like agent Mulder, he believed the truth was "out there"). ${ }^{1}$ He also knew that our fascination with extra-terrestrials is more about our own alienation, our own strangely anxious and hopeful sentience, than it is about imagined alien

1 This chapter is an adapted version of "Theology After Pandora: The Real Scandal of the Evangelical Mind (and Culture)," which was originally published in a posthumous Festschrift for Stan Grenz, ed. Tidball et al., Revisioning, Renewing, Rediscovering the Triune Center (Eugene, OR: Wipf and Stock, 2014).

(C) F. LERON SHULTS, 2018 | DOI 10.1163/9789004360952_008

This is an open access chapter distributed under the terms of the CC BY-NC-ND 4.o license. Shults - 9789004360952 
creatures. More than most evangelical theologians, Stan focused on what was happening here and now on planet Earth. Nevertheless, like every other evangelical I know, he also anticipated an eschatological renewal of this world, a new Earth (and a new Heaven), re-created in some sense by the supernatural agency of Christ. In this chapter I borrow one of Stan's well known methodological strategies, reflecting on theological themes in the context of engaging a popular science fiction film. Although he almost certainly would not have agreed with my material proposal, I know he would have welcomed the conversation.

One might think that the reference to "Pandora" in the main title of this chapter was to the Greek myth in which the first woman, modeled of clay by Hephaestus as part of Zeus's punishment of mankind for Prometheus' theft of fire, released evils into the world by opening a box (or jar) given to her by the gods. At the end of this Chapter we will return to poor Pandora, but the reference here is actually to the planet Pandora in the 2009 film Avatar. The film portrays the conflict between the Na'vi, the (mostly) friendly natives of Pandora, and the invading human forces of the RDA mining corporation, the (mostly) nasty humans bent on acquiring the aptly named "unobtainium" that lie buried beneath the surface of the planet. I use this fictional account of a conflict of ideas and societies on Pandora as material for reflecting on the possibilities for theology to respond in new ways to the intellectual and political challenges we face here and now on planet Earth.

In his influential book on The Scandal of the Evangelical Mind, Mark Noll begins by asserting that "the scandal of the evangelical mind is that there is not much of an evangelical mind... American evangelicals have failed notably in sustaining serious intellectual life." ${ }^{2}$ In his more recent Jesus Christ and the Life of the Mind, Noll finds some signs for modest optimism but remains "largely unrepentant" of his negative evaluation. ${ }^{3}$ Stan Grenz was an obvious exception. His scholarship set a standard of excellence among those who selfidentified as part of the North American evangelical subculture. Fundamentalists were often scandalized by his writings, not for Nollian reasons, but because he challenged the status quo they were so concerned to protect. Nevertheless, the existence of a few such scholars does not diminish the larger point: Noll is right to decry the lack of intellectual rigor among evangelicals. The problem, however, is much deeper and more serious than Noll realizes.

The real scandal of the evangelical mind, I will argue, cannot be separated from the scandal of the evangelical culture, and vice versa. Balancing

2 Noll, The Scandal of the Evangelical Mind (Grand Rapids, Mich.; Wm. B. Eerdmans Publishing Co., 1995), 3 .

3 Noll, Jesus Christ and the Life of the Mind (Grand Rapids, Mich.: Wm. B. Eerdmans Publishing Co., 2013), 105 . 
piety with more appreciation of the Christian intellectual tradition will not solve the problem. Balancing social concern with better scholarship will not solve the problem. Such efforts merely reorganize the chairs on the deck of the sinking Titanic (to allude to another film by James Cameron). The deeper problem facing evangelicalism is one that is shared by other religious coalitions. Although the material details of evangelical belief in and hope for eschatological renewal have their own peculiarities, they are formally structured by the same evolved dynamics that have contributed to the emergence of religion in every known human society: widely shared imaginative engagement with axiologically relevant supernatural agents.

Evangelicals will continue to stumble as long as they cannot see the hidden cognitive and coalitional mechanisms that shape their mental and social life. This chapter is an attempt to unveil these mechanisms by engaging recent scientific discoveries about (and philosophical reflection on) the emergence, evolution, and transmission of human religiosity. Once we can see what we are doing, it will be easier to explore new possibilities for the discipline of theology. In the concluding section of this chapter, I propose a way of doing theology that does not appeal to extra-terrestrials (or supernatural agents) who favor a particular human coalition. For reasons I will try to make clear, I call this the iconoclastic trajectory of theology.

The first three sub-sections set out the basic argument of the chapter. First, I provide yet another overview of the conceptual framework of theogonic reproduction theory, which we have been discussing in earlier chapters. Second, I use this framework to analyze the "theological" options portrayed in the movie Avatar, as the (increasingly) evil capitalists fight the (initially) naïve tree-huggers for control of the planet Pandora. This then sets the stage for a description of evangelical groups as examples of a particular kind of supernatural agent coalition, typical of those religions that trace their roots to the axial age, which normally follow what I call the sacerdotal trajectory of theology. The real scandal of the evangelical mind (and culture) is that evolved mechanisms are surreptitiously shaping its theological practice, reinforcing the psychological repression and political oppression that everyone sees but no one is sure what to do about. The last two sub-sections explore the possibility of a quite different approach to doing theology.

\section{Bearing Gods in Mind and Culture}

Why are we religious? As we have seen, empirical findings and theoretical reflections across a variety of fields including archaeology, cognitive science, evolutionary neurobiology, moral psychology, social anthropology, and 
political theory suggest that the contemporary human beliefs, activities, and emotions normally associated with "religion" are shaped by naturally evolved mechanisms that are part of our shared phylogenetic heritage. This section provides another introductory and integrative reading of significant trends within these fields, which coalesce around the general claim that shared ritual interaction with gods naturally emerges in contemporary human minds and cultures as a result of cognitive and coalitional tendencies that helped our early hominid ancestors survive in small-scale groups, granting them a competitive advantage in an upper Paleolithic environment. The question that faces us today is whether these tendencies are still adaptive in our rapidly changing, pluralistic, global environment.

First, let me reiterate the sense in which I am using some key terms. The term bearing has a double meaning, indicating the naturally evolved processes by which gods are born in human cognition (by the hyper-active detection of agency in the natural environment) and borne in human culture (by the hyper-active protection of coalitions in the social environment). When I refer to these mechanisms as theogonic (god-bearing), I am not alluding to literary accounts of the genesis of the gods such as Hesiod's Theogony, but to the way in which such bio-cultural mechanisms engender any and all narrative imaginative engagement that reinforces the human desire to participate in religious sects.

As we have seen, scholars in the disciplines that contribute to the bio-cultural study of religion often use the term god as shorthand for any culturallypostulated, discarnate intentional force - as synonymous with "supernatural agent" or "superhuman entity." In other words, not only Yahweh, Zeus, or Vish$\mathrm{nu}$, but also ghosts, genies, and goblins would be referred to as gods. The differences between these kinds of gods are obviously significant, but for the sake of participating in this interdisciplinary dialogue I will follow this usage in this chapter. At this point, it is important to note that they all share at least two key features: intentionality and contingent embodiment.

A supernatural agent coalition is a social nexus that is held together, at least in part, by appeal to the power or authority of gods allegedly watching the group and concerned about its members' evaluative (or axiological) judgments or moral actions. ${ }^{4}$ That is to say, the way in which members of the group evaluate one another's (and their own) beliefs, behaviors and attitudes are in some way constituted or regulated by supernatural agents who are taken to be strategic players in the survival of the group. All of this leads to my use of the

4 See, e.g., Bulbulia, "Nature's Medicine: Religiosity as an Adaptation for Health and Cooperation," Sosis, "Religious Behaviors, Badges, and Bans," and the other references from Chapter 1 in the current volume. 
term religion in this context to refer to "shared imaginative engagement with axiologically relevant supernatural agents."

With these definitions in place, I now return to another discussion of the conceptual grid we have been exploring (Figure 1, Chapter 1, p. 3), but this time focusing on the way in which it can help us differentiate between two trajectories in the discipline of theology. As we have seen, this initial fractionation of theogonic mechanisms (anthropomorphic promiscuity and sociographic prudery) does not capture all the complexity of "religion," but this framework is sufficient for its purpose; namely, as a heuristic device for discussing the interactions between two basic tendencies that are part of the phylogentic inheritance of all Homo sapiens (including evangelicals).

Once more (and for the last time in this volume), let's review the basic tenets of theogonic reproduction theory. As we have seen, the integration of mechanisms that engender anthropomorphic promiscuity and sociographic prudery was an evolutionary winner. In the early ancestral environment the selective advantage went to hominids whose cognitive capacities enabled them to quickly detect relevant agents (such as predators, prey, protectors, and partners) in the natural environment, and whose groups were adequately protected from the dissolution that could result from too many defectors and cheaters in the social environment.

Hyper-sensitive detection often led to false positives; e.g., identifying a noise in the forest as a predator (or prey) when it was really the wind. However, occasionally it really was a predator (or prey) and those whose detective capacities were weak or lazy - it's probably just the wind - got eaten (or failed to eat) and so their genes were not passed on. Hyper-sensitive protection often led to serious punishment of cheaters, the demand for costly signals of commitment from those suspected of considering defection, and willingness to attack and kill members of out-groups. The good news (for the in-group) is that these strategies did in fact lead to stronger (longer-lasting) coalitions.

In fact over-sensitive detection and protection (and other components of anthropomorphic promiscuity and sociographic prudery) increased the chance of survival during a critical period of time in human history. In earlier chapters, we reviewed part of the growing body of evidence that suggests that around 90,000-70,000 years ago, some Homo sapiens groups developed more complex beliefs and rituals in which they imaginatively engaged supernatural agents they detected in the environment (e.g., spirits attributed responsibility for weather, good hunting, etc). These contingently embodied (or ontologically confused) intentional forces were often believed to have the power to punish cheaters or defectors (or their family members). They also might be watching at any time, which increased group member's motivation to follow 
social norms. Sometime around 6o,ooo years ago it appears that some of these "god-bearing" groups left Africa, out-competing all other hominid species and spreading out across the Levant and into Europe and Asia, eventually incorporating other kinds of supernatural agents such as ancestor-ghosts.

All living humans are the genetic offspring of these groups, and so share a suite of inherited traits (differentially distributed across the population) that support the tendency to detect supernatural agents and protect supernatural coalitions. In other words, most human beings today are intuitively and "naturally" drawn into the lower left quadrant of Figure 1. These evolved traits were tweaked differently in various contexts, which led to the diversity of manifestations of religious life we see across cultures of gods. Conceptions of gods are never immaculate; the particular features of our supernatural agents give away our religious family of origin.

During the axial age (circa 800-200 B.C.E.), the challenges of pluralism and organizational hierarchy in complex literate states across west, south, and east Asia required more complicated and stronger forms of coalition. In other words, bigger cultures needed bigger gods. In the monotheistic religions that trace their roots to Abraham (Judaism, Christianity, and Islam), this took the form of belief in an infinite person-like Supernatural Agent who has power over all Coalitions whatsoever. These religions are sacerdotal insofar as they require their members to signal commitment to the group by costly participation in "priestly" rituals that are intended to mediate the power of the "sacred."

When theology follows this sacerdotal trajectory, it reinforces detection of a particular Supernatural Agent concerned about the well-being (and obedience) of a particular Coalition. In other words, it canalizes and facilitates the unchecked operation and integration of the theogonic mechanisms depicted in the lower left quadrant of Figure 1. Such an organizational strategy worked relatively well for centuries, at least from the perspective of those Coalitions whose crusades against and colonization of religious others enhanced their own prosperity.

\section{Avatar Theology}

What does any of this have to do with the imaginary planet of Pandora? Like most science fiction, the movie Avatar portrays a mixture of dystopian and utopian idealizations projected from the writer's own anxieties or hopes about human society. As far as we can tell, nothing like an axial age had occurred on Pandora; the writers depict the Na'vi (and other indigenous tribes) as an odd combination of shamanic small-scale clans and proto-barbarian despotic 
states. The RDA corporation is a stereotypical organizational cog within an industrial-military complex, driven by nothing more than a lust for more profit. Some of the scientists hired by RDA, however, want to study (and perhaps even learn from) the Na'vi.

As we saw have seen, most human beings on planet Earth have evolved dispositions that collectively encourage them to bear the gods of their own in-group. The two main groups combating in the movie Avatar, the Na'vi and the RDA, can be taken as representatives of social assemblages that have been primarily shaped by two of the machines we discussed in Chapter 6: the territorial and the capitalist social-machines (respectively). Although social-machines cannot be plotted onto the same plane as the cognitive and coalitional tendencies registered on our coordinate grid (Figure 1), we might imagine them as operative in a third dimension that creatively interacts with those individual level variables (or perhaps as Gaussian curvatures, or even shifting time-space curvatures within a Riemannian manifold, that intersect with them under various parametric conditions).

At any rate, focusing initially only on the coordinate grid, we can say that most of the Na'vi are anthropomorphically promiscuous: supernatural agency is detected at work in moss, trees, animals, and mountains. Many of the Na'vi are quite open (at least initially) to other modes of inscribing the socius, enthusiastically sending their children to the school run by the RDA scientists. The corporate leaders of $\mathrm{RDA}$, on the other hand, are anthropomorphic prudes, refusing to acknowledge even the human-like agency of the Na'vi, whom they refer to as "blue monkeys." Members of the RDA coalition are also quite prudish in their sociography (although not in the "religious" sense), forcing their own norms upon others, with little patience for anything that challenges their capitalist inscriptions.

What does any of this have to do with theology? For the sake of this chapter, let us work with a broad definition of this field of inquiry: theology as the critique and construction of hypotheses about the existential conditions for finite axiological engagement. In this sense, both the Na'vi and RDA have their own "theologies." Each group has its own (more or less explicit) shared hypotheses about that which makes possible their experiences of valuing and being valued by others. Here we are not talking about this or that particular value, but that which generates the conditions for all valuation whatsoever. Now the sacerdotal trajectory in theology, by far the most common on Earth since the axial age, develops hypotheses that appeal to particular supernatural agents and their coalitions; "our God" is the basis of and judge over all values and actions. I will return below to the upper right quadrant, in which we can trace what I have called the iconoclastic trajectory of theology. 
The typical ways in which members of the Na'vi tribe and the RDA corporation tend to make sense of the conditions for finite axiological engagement illustrate what I call the prodigal and the penurious trajectories of theology. These theological trajectories are buoyed by the integration of cognitive and coalitional tendecies that are integrated in the upper left and lower right quadrants of Figure 1 (respectively). We can call the trajectory in the upper left corner prodigal because it is promiscuous in relation to both the cognitive and coalitional tendencies; i.e., it can lead to an extravagant expenditure of energy on imaginative engagement with supernatural agents (ubiquitous detection of intentionality) and on profligate pursuit of ever new experiences with other groups (inadequate consolidation of sociality).

The theological trajectory that gravitates toward the lower right quadrant of Figure 1 is penurious in the sense that it is stingy in relation to both types of evolved mechanisms; i.e., it can lead to a tightfisted refusal to acknowledge members of out-groups (failure to "see" actual, natural intentional agents), and miserly resistance toward sharing with and learning from other cultures (stubborn maintenance and expansion of in-group norms). Of course, the RDA capitalists are not sociographically prudish in the specifically religious sense articulated in Chapter 1; they do not try to validate their norms by appealing to supernatural authorities. Nevertheless, we can see how anthropomorphic prudery and at least some of the component mechanisms that undergird sociogaphic prudery are at work in the cognitive interpretations and normative inscriptions of the leaders of the RDA.

The main point here is that these trajectories represented by the Na'vi and the RDA are indeed theological. What is it that makes possible (perhaps even originates, orders, and orients) value-laden engagements? The hypothesizing that guides the prodigal trajectory of the Na'vi is characterized by a relatively loose and open interaction with a pervasive field of supernatural agency that (early in the story) is not specifically concerned with protecting a particular coalition. The penurious hypothesizing of the RDA is guided by a strict allegiance to the invisible (yet quite "natural") hand that guides the flow of capital-money, and whose alleged neutrality justifies the behavior of those who learn to control it.

In the movie, the planet Pandora is portrayed as actually infused with the supernatural energy of a mother tree-goddess who (spoiler alert) eventually makes the animals of the planet fight against RDA. Jake Sully (the hero) becomes a kind of warrior-priest who is able to convince her of the evil of RDA. Because of her supernatural intervention, the RDA is thwarted and forced to leave the planet; the Na'vi coalition is saved.

But let's come back to Earth. Clearly there are some groups on our planet too who resemble the RDA and others who live somewhat like the Na'vi. 
However, neither of these theological strategies will be adequate for saving our planet; in our late modern, pluralistic, globalizing context, we will not be able to live together under these conditions. As several cinematic observers pointed out, the movie Avatar is rather obviously intended as a negative commentary on U.s. interventions in the Middle East. The Colonel with a southern accent (George W. Bush?) and the RDA Administrator in charge of doling out contracts (Dick Cheney?) are blind to everything but the "unobtainium" (oil) hidden under the land of indigenous peoples (Iraqis, Afghanis, etc.).

My point here is that although we may well celebrate the movie's denigration of the trajectory represented by RDA, we humans do not actually live on Pandora and so the trajectory represented by the Na'vi is also doomed to fail. If in fact there were tree-goddesses to whom the colonized worldwide could appeal, things would be different; invading forces (military or economic) could be defeated by petitioning such supernatural agents who could harness the powers of nature. But there are not. And they cannot. Earth is not Pandora. I believe that the upper right quadrant is our best "theological" option. Before exploring this possibility, however, let me back up and demonstrate the way in which contemporary evangelicalism illustrates the sacerdotal trajectory, which has been the most popular mode of theological hypothesis construction for the last two millennia here on Earth.

\section{Evangelical Supernatural Agent Coalitions}

First, what is an "evangelical"? The question is not merely academic, as Stan Grenz, and those who tried to exclude him from this category, knew quite well. For my purposes, it suffices to use a broad definition of the term, referring generally to those who participate in religious coalitions shaped byvarious attempts in the mid-2oth century (by the likes of Billy Graham) to find a middle way between fundamentalism and liberalism in Christianity. Such groups have achieved dominance in many areas in the United States and Britain, and continue to expand in many parts of the world, including my new homeland of Norway. Although this was my own religious "family of origin," I did not know how important this appellation was until I was informed of my "evangelical" identity at college.

Now many (but certainly not all) evangelicals would laugh at the idea of a tree-goddess who controls animals and cares about a small-scale coalition. However, most evangelicals do imaginatively detect a whole host of ambiguously discarnate or contingently embodied intentional forces who are interested in their coalition: angels, demons, disembodied ancestors (saints), etc. They also believe in a powerful and wise Supernatural Agent who will punish cheaters and defectors and protect those who remain faithful to an in-group, rewarding 
them with a place in an everlasting heavenly Coalition. The fact that members of out-groups (other religions, or even other sorts of evangelicals who disagree on some point of polity or biblical interpretation) believe that their coalitions will be protected by the gods (or God) that they have detected is explained away as the result of demonic delusion or even sin. In my view, this appeal to the noetic effects of sin is one of the most appalling of noetic sins. But I digress.

While most evangelicals find themselves comfortably in the sacerdotal trajectory (the God we detect protects our Coalition), it is interesting to observe how differently their right and left wings typically respond to the other two trajectories so far explored. In my experience, those on the evangelical "right" are usually more worried about New Agers (the prodigals) than they are about capitalist corporations that ravage the poor and the environment (the penurious). On the other hand, those on the evangelical "left" tend to react more harshly to RDA types and are less anxious about the touchy-feely spiritualism that characterizes some recent forms of the ecclesial socius. Which is more important - rejecting the (interpretation of) gods detected by others or expanding our own coalition by loosening social norms?

Wherever evangelicals fall in their answers to such questions, they remain within the sacerdotal trajectory. Here they are in good (or at least plentiful) company. Like the other Abrahamic religions, evangelical coalitions are held together by shared imaginative engagement with particular kinds of contingently embodied intentional forces. These may be explicitly divine figures detected at rituals (the presence of Jesus at the Eucharist, the Holy Spirit at a baptism) or lesser supernatural agents detected in everyday life (an angel when in need of protection, a demon when feeling temptation, a former saintly coalition member when in need of inspiration).

Evangelicals may be well trained in theological doctrine, and give orthodox answers to questions about divine infinity, immutability, aseity, and omniscience, but (like everyone else) they easily fall back into "theologically incorrect" models of God as a human-like intentional entity who is emotionally concerned with the struggles of their coalition in real space and time. This is because the evolved theogonic mechanisms naturally lead people to imagine finite gods who are watching over small-scale groups. ${ }^{5}$

Most professional theologians (at least in America) are paid by institutions that support a particular religious coalition or set of coalitions that follow the sacerdotal trajectory. A great number of these institutions require faculty to sign a "statement of faith," signaling their commitment to the in-group. As one

5 See, e.g., Barrett, "Dumb Gods, Petitionary Prayer and the Cognitive Science of Religion," and Slone, Theological Incorrectness. 
example, let us take the institution with which Mark Noll has been associated for much of his career. Wheaton College demands that the scholars it employs the "evangelical minds" it hires - assert and re-assert every year that they believe inter alia in supernatural agents like Satan, that out-group members will be punished eternally, that a text revealed by a supernatural agent is the final authority on all matters it discusses, and that physical death entered the world when Adam and Eve, the historical parents of the entire human race, disobeyed God. ${ }^{6}$

Similar claims could be culled from other statements of faith imposed by hundreds of similar institutions. But let us set aside for a moment the plausibility of particular assertions within such statements. The very fact that intellectual exploration is policed and restricted by forcing scholars to limit their claims (in any field) to assertions that are consistent with a particular coalition's appeal to supernatural agents (which only they can appropriately detect and properly interpret) is a symptom of the real scandal of the evangelical mind (and culture).

Stan Grenz was a leader in reforming, renewing, and revisioning evangelical theology. ${ }^{7}$ His efforts were consistently attacked by those who were afraid that his intellectual rigor and engagement with contemporary culture and science were a threat to their own coalitions. I always admired Stan's courage and integrity in setting out his positions. He was the epitome of irenicism and never insisted that someone agree with him before (or after) engaging in serious theological conversation. I'm quite sure he would have resisted the radical proposals that I set out in the next section, but equally sure he would have encouraged me to tell it like I see it.

\section{Iconoclastic Theology for Terrestrials}

We do not live on Pandora. There are no tree-goddesses to save us. Those of us who agree that unbridled capitalism requires an infinite expansion of resources, and is rapidly depleting our finite ecological limits, have little faith in the RDAs of planet Earth. Given our evolved tendencies to detect supernatural agents, and our social entrainment within west Asian religious traditions, it is easy to believe that our only and best option is the sacerdotal trajectory. This

6 http://www.wheaton.edu/About-Wheaton/Statement-of-Faith-and-Educational-Purpose. Accessed 15 August 2017.

7 His extensive corpus was engaged by other chapters in the Festschrift of which the original version of this chapter was a part. Examples of his efforts at reformation include Grenz, Renewing the Center: Evangelical Theology in a Post-TheologicalEra (Grand Rapids, MI: Baker Academic, 200o); Grenz, Revisioning Evangelical Theology (Downers Grove, IL: IVP Academic, 1993). 
adaptive strategy may have worked well (in terms of holding together complex social groups) during the axial age but the integration of these cognitive and coalitional mechanisms lead us to misinterpret ambiguous natural events (like tsunamis) or to ignore clear natural events (like global warming), appealing instead to supernatural causes or promises.

The same evolved dynamics that aid in the coalescence and maintenance of relatively large religious coalitions, like evangelicalism, also fuel antagonism toward perceived in-group defectors (like Stan Grenz) and a willingness to sanctify violence against out-groups. The sacerdotal trajectory helped some members of the species to hold together during a difficult period, but the exponential growth and rapidly increasing global connectedness of the human population require new ways of constructing and criticizing hypotheses about the conditions for axiological engagement.

How could evangelicals possibly participate in the iconoclastic trajectory of theology, which resists the evolved tendencies to over-detect agency and over-protect groups, and gravitates toward the upper right corner of Figure 2 (Chapter 1, p. 64)? After all,this trajectory is diametrically opposed to the theogonic forces that have nurtured their traditions for centuries. In fact, many Christian theologians have indeed followed the iconoclastic trajectory - at least sometimes, at least partially. The real question is whether they can follow it consistently. I call this trajectory "iconoclastic" because the integration of theolytic tendencies has a jarring, and potentially destructive, effect on the religious images (icons) shared by members of a religious coalition, weakening their explanatory and cohesive power. When theologians follow this trajectory, they construct and criticize hypotheses about the conditions for axiological engagement without immediately appealing to a particular supernatural revelation or to the rituals and social norms of their in-group. In other words, they become more sociographically promiscuous and anthropomorphically prudish.

Before offering examples of this iconoclastic trajectory in theology, let me illustrate the integration of these theolytic mechanisms in non-theological scholarship. In sciences such as physics and chemistry, for example, scholars resist (or at least try to resist) the tendency to appeal to discarnate intentional forces or to the beliefs of politicized organizations with some investment in the research. If something strange happens in a test tube, the chemist's first guess is not "ghost." If a laboratory heavily funded by a pharmaceutical company announces that the drug produced by that company is more effective than previously thought, other scientists will remain skeptical until the research is repeated by another group. Even in sciences like sociology and political theory, which do indeed need to detect human agents and whose subject matter includes the dynamics of group cohesion, their scientific explanations of these phenomena do not appeal to supernatural agents or insights available only 
through revelation to a particular coalition. If they did, they would not be taken seriously as scholars. Anthropomorphic prudery and sociographic promiscuity are promoted by participation in academic communities.

What about theologians? Can someone who is anthropomorphically prudish and sociographically promiscuous still be a theologian? Yes, in a sense. In fact, many Christian theologians (and even some evangelical theologians) do resist the idea of God as a coalition-favoring, contingently-embodied "person." The problem is that movement in the iconoclastic (upper right) direction on the coordinate grid of Figure 1 is almost always pulled back down (toward the lower left) by the powerful forces of the theogonic mechanisms. The sacerdotal trajectory relatively easily and "naturally" overrides the iconoclastic trajectory because the vast majority of theologians are operating within coalitions whose cohesion depends on shared imaginative engagement with supernatural agents. A first step for theologians interested in pursuing the iconoclastic trajectory - if they dare - is to trace and liberate lines of flight already present within the axial age religions, in which they are expert; for evangelicals, this usually means Christianity.

We can identify at least three different pathways or modes of intensification, already present (albeit suppressed) in the Christian tradition, which lead in this direction. The first is what I call the intellectual mode, in which the intensification of conceptual analysis leads to a recognition of the logical impossibility of the idea of an infinite Supernatural Agent. If "the infinite" cannot be thought as one object distinct from "the finite," else it would be limited by the finite and so itself finite, then a forteriori it cannot be thought of as one supernatural person distinct from other persons, who favors one polity distinct from other polities. This is the pathway (partially) taken by most of the leading theologians of the axial age religious traditions. Stan Grenz's robustly trinitarian theology is an excellent example; he clearly saw the logical problems with the idea of a single infinite subject.

A second mode is pragmatic; here, the intensification of compassionate action leads to liberating efforts on behalf of those oppressed or excluded by the dominating policies of the elite within a supernatural agent coalition. Many evangelicals, especially those interested in challenging the racism, sexism, and classism within their coalitions have proactively developed new ways of inscribing the socius and questioned the extent to which particular interpretations of supernatural agents (and their role in personal and social transformation) are necessary conditions for fellowship. It is easy to see why such "emergent" movements are so vigorously and violently vilified by the (white, male, upper middle class) evangelical power elite. In fact, reaching out with authentic openness to members of out-groups (and defectors, like 
ex-evangelicals) is indeed dangerous for such religious in-groups, whose cohesion depends on clear statements about the boundaries of faith.

Third, there is a mystical mode in which the intensification of contemplative awareness leads to experiences that alleviate anxiety about being-limited by an infinite person-like supernatural agent and the need to protect the power of a particular group. One can find examples of this mode within all of the religious traditions that trace their roots to the axial age, and often evangelicals who begin to follow this trajectory explore meditative practices that evolved within other traditions (e.g., Buddhism, Daoism, Sufism, etc.).In Christianity, this mode is often linked to the apophatic way, in which the power of human language to comprehend the divine is rigorously denied. Evangelicals are permitted to express their ignorance about the essence of a transcendent supernatural agent, as long as they also express their confidence in kataphatic statements about the anthropomorphic attributes of that agent. In other words, the risky adventure of the iconoclastic trajectory must be domesticated by the sacerdotal.

For obvious reasons, most theologians have preferred the intellectual pathway. Not uncommonly, however, concerns about the plausibility of the idea of God (as an infinite Supernatural Agent who favors a human coalition) are driven by moral and aesthetic sensitivity as well as by conceptual reflection. It is important to ask why it is usually systematic theologians, rather than biblical scholars or historians (like Noll), who get drawn into evangelical heresy trials. Scholars of Scripture or Christian history are not required, and indeed sometimes actively discourage one another, from trying to provide a coherent account of the discrepancies within the texts and disparities across the eras they study. Systematic theologians, on the other hand, are pressured to follow out the logical implications of the assertions of their religious coalitions as far as possible - before appealing to mystery. If a theologian follows the intellectual mode too far, she gets in trouble. This is the real scandal of evangelical culture and its oppression of evangelical minds.

Noll decries the lack of integration between intellectual rigor and piety in evangelicalism. This is only a symptom, not the root, of the problem. Insofar as pious devotion imaginatively engages ritually-mediated, discarnate intentional forces concerned about "my" in-group, it is the hyper-active detection of coalitional gods - postulated as causal explanations for ambiguous natural phenomena. Insofar as pious activism is driven by an attempt to participate in and expand the kingdom of "our" God, it is the hyper-active protection of a supernatural coalition - interpreted as the best way to inscribe the global socius. In this sense, piety directly compromises inter-subjective discourse about natural phenomena and inter-communal discourse about social phenomena. It cannot be integrated with the intellectual rigor that is characteristic 
of the other sciences, which attempt to follow the trajectory in the upper right corner of Figure 2 (Chapter 1, p. 64).

Sacerdotal appeals to "mystery" use the in-conceivability of infinity as a veil of ignorance - a learned ignorance that veils the hyperactivity of the religious family's shared imaginative engagement with their God. The inability of finite creatures to conceive the infinite (or even all finite things) suggests an (infinite) vacuum in human knowledge. Abhorred, the theogonic mechanisms quickly and easily fill it by detecting and protecting manifestations of a particular coalition's supernatural agent.

In contrast to the domesticating effect of the sacerdotal forces, the iconoclastic trajectory of theology de-personifies, de-politicizes and, in a certain sense, de-objectifies the existential conditions for axiological engagement. It is true that the "object" of theology is not like the objects of other disciplines; the relation between infinity and intentionality cannot be objectified like finite relations. That which conditions the existence of all finite valuations cannot itself be finite or even evaluated in the same sense. Rather than using this as an excuse for appealing to the mystery of a particular coalition's interpretation of a supernatural agent, however, the iconoclastic (a)theologian can explore other ways of making sense of this being-limited of thought (or being-thought of limitation) which can indeed be "objectified" (as the reader is currently doing).

The integration of anthropomorphic prudery and sociographic promiscuity is not merely destructive of religious images; as we can see from the other sciences, these theolytic forces also have a creative power. They can facilitate the construction of new hypotheses about the conditions for axiological engagement that avoid personifying or politicizing "infinity." I do not have the space to set out such a proposal here, so I devote the remainder of the chapter to a discussion of the possibility and promise of this iconoclastic trajectory. ${ }^{8}$

\section{Theology after Pandora (and Eve)}

Back to Pandora - but not the planet this time. The ancient Greeks were not the only ones to develop a myth in which the actions of the first woman are blamed for the evils in the world. Like Pandora, Eve's curiosity was supposed to have killed the race - or at least its chance for immortality. New and other gods would be invented; (mostly) male heroes whose supernatural powers would provide remedies for humanity.

8 For a detailed discussion of the iconoclastic trajectory in theology, see Shults, Iconoclastic Theology. 
The stories of Pandora and Eve teach us that it is dangerous (especially for women) to question divine things, to look into the forbidden black boxes of divine intentionality. Inquiring too persistently into the mechanisms by which discarnate intentional forces punish and reward us threatens the shared imaginative engagement that holds the coalition together, and so it is taboo. As long as evangelicals, or members of any other religious in-group, protect the cohesion of their communities and institutions by encouraging detections of hidden supernatural powers only "we" know how to interpret by, for example, insisting that theologians sign coalitional statements of faith, they will not ever be able to engage in serious constructive scholarship in dialogue with other sciences.

I was an evangelical theologian long enough to know how my friends and former colleagues might respond to such claims. St. Paul claimed that God uses the "folly of what we preach to save those who believe," and that Christ crucified is "a stumbling block to Jews and folly to Gentiles" (1 Cor. 1:21-22). Blessed are those who are not scandalized, but signal their commitment to the coalition by faithfully adhering to apparent foolishness. Similar texts and similar strategies are present in other religions.

But why accept the Bible as the revelation of a Supernatural Agent in the first place? Why not accept the Qur'an, the Book of Mormon, or the Dhammapada instead? Human beings have evolved cognitive and coalitional mechanisms that short-circuit such questions. We know that our (interpretation of) shared imaginative engagement with our supernatural agents is true. Every other religious group (or denomination) says the same thing. At best, their leaders come to abstract "inter-religious" agreements that have little effect on everyday religious practice. At worst, they start "holy" (or "just") wars against one another. Is it any wonder that intellectuals in other fields hesitate to take (sacerdotal) theology seriously?

Several other objections will certainly arise from my religious family of origin. Wouldn't my proposal for taking more seriously the discoveries of the bio-cultural study of religion mean the dissolution of evangelicalism, indeed the destruction of Christianity itself? Doesn't the fact that Shults has clearly gone off the deep end prove that, in fact, engaging modern science and culture really is dangerous - too dangerous? Perhaps the conservative Christian political "right" is correct; sectarianism may be the only hope for protecting the purity of particular Christian coalitions.

I have several responses to these kinds of questions and concerns. First, we should begin by admitting that the dissolution of other supernatural coalitions is exactly the goal of most Christian evangelism and missions. If evangelicals want believers in other supernatural agents (whom they take to be "false" gods) 
to consider with all seriousness that they may be wrong, they should be willing to take their own medicine.

Second, do evangelicals want to believe what is true or do they want what they already believe to be true? Is being a Christian, or an evangelical, more important than being right - or even making sense? We have evolved to think that fitting into our coalition is indeed the most important thing in the world. We have learned to stifle our questions about the contents of the divine "black box" hidden in plain sight in the religious imagination and rituals of our ingroups. We are cognitively and coalitionally wired to ignore the psychological repression and political oppression caused by our own religious tribes.

Scholars, activists, and contemplatives are trained not to ignore them. My challenge to evangelicals who are also iconoclasts (in any of the three modes of intensification) is to take seriously the importance of the following questions: is contemporary shared imaginative engagement with supernatural agents the result of evolved hyper-active perceptive and cooperative strategies that helped our ancestors survive in small-scale societies? Are these strategies now obsolete in a complex, pluralistic social environment? If so, what can we do about it?

Third, iconoclastic theology does not necessarily lead to the destruction of social groups; the complete dissolution of evangelical coalitions is not the only option here. Like many other such religious in-groups, evangelicals have played an important role in developing strategies for caring for human persons and coalitions, including out-groups. The hard work ahead for the iconoclastic theologian (or activist, or contemplative) is to imagine and enact new and creative ways to live in community that do not rely on the mechanisms of the sacerdotal trajectory. This may very well, indeed we should expect that it would, include forms of axiological engagement that are inspired by exemplars like Jesus of Nazareth (among others). ${ }^{9}$

The best hope for theologians to join with other scholars of religion in serious inter-disciplinary conversation, and to participate with other groups in serious inter-cultural conversation, is to liberate the iconoclastic trajectory from the sacerdotal. Like their colleagues in other disciplines, theologians must learn to resist the evolutionary biases that make it so easy for people to keep engaging in religious sects. This does not at all mean giving up on the real intensity of the human experience of being-limited, the intense reality of beingconditioned in all of our axiological engagements. Reflecting on these really intense experiences of encountering infinite intensities remains an important task in human life.

9 Shults, "Ethics, Exemplarity and Atonement" in Theology and the Science of Moral Action, ed. van Slyke et al. (Routledge, 2012). 
Even if we could reconstruct this discipline into a critique of axial age religious conceptions and new hypothesis-construction, would it be appropriate to call it "theology?" In fact this term has been used historically, from Aristotle to Zizek, ${ }^{10}$ to refer to arguments about the existential conditions for human axiological engagement that do not appeal to human-like, coalition-favoring gods. In the long run, whether or not we keep the term "theology" is less important than undertaking the task of reconstructing this mode of inquiry so that it can fully enter into the important, ongoing academic dialogue on these issues. This can only happen if we honestly discuss how God is born(e) among us, however embarrassing the "facts of (religious) life" may be to evangelical (and other sacerdotal) theologians.

10 Aristotle, Metaphysics 1025a.19, 1064b.3; Slavoj Žižek, The Parallax View (Cambridge, MA: MIT Press, 2009). 